Tropical Journal of Pharmaceutical Research July 2016; 15 (7): 1499-1505

ISSN: $1596-5996$ (print); 1596-9827 (electronic)

(C) Pharmacotherapy Group, Faculty of Pharmacy, University of Benin, Benin City, 300001 Nigeria.

All rights reserved.

Available online at http://www.tjpr.org

Original Research Article

http://dx.doi.org/10.4314/tjpr.v15i7.21

\title{
Protective effect of rhamnopyranosyl vanilloyl isolated from Scrophularia ningpoensis Hemsl (Scrophulariaceae) root against acute liver injury in mice
}

\author{
Chang-Wu Wang ${ }^{1 *}$ and Xin-Hui Fang ${ }^{2}$ \\ ${ }^{1}$ Department of Gastroenterology, the Fifth Affiliated Hospital of Zhengzhou University, ${ }^{2}$ Department of Gastroenterology, \\ Henan Province People's Hospital, Zhengzhou 450000, PR China
}

*For correspondence: Email: cwwang_zz@sina.com

Received: 15 October 2015

Revised accepted: 4 June 2016

\begin{abstract}
Purpose: To investigate the protective effect of rhamnopyranosyl vanilloyl (RV) from Scrophularia ningpoensis root against tetrachloromethane $\left(\mathrm{CCl}_{4}\right)$-induced acute liver injury $(\mathrm{ALI})$ in mice.

Methods: RV was isolated from S. ningpoensis by column chromatography. ALI model of mice was established by intraperitoneal injection of $\mathrm{CCl}_{4}$. Liver index, liver function indices, as well as serum alanine transaminase (ALT), aspartate aminotransferase (AST) and total bilirubin (TBIL) were evaluated. Lipid peroxidation (LPO)-related indices, including malonaldehyde (MDA), glutathione (GSH), superoxide dismutase (SOD) and glutathione peroxidase (GSH-Px). Apoptotic proteins (Bcl-2, Bax and caspase-3) in liver tissue were determined by enzyme-linked immunosorbent assay (ELISA) and Western blot.

Results: After treatment with RV (10, 20 or $40 \mathrm{mg} / \mathrm{kg}$ ), liver index (5.65 - $5.21 \mathrm{vs.} 6.68 \%$ ), ALT (90.18 79.68 vs. $112.47 \mathrm{U} / \mathrm{L})$, AST (64.44 - $57.63 \mathrm{vs.} 75.41 \mathrm{U} / \mathrm{L})$ and TBIL (2.68 - $1.95 \mathrm{vs.} 3.21 \mathrm{U} / \mathrm{L})$ activities, as well as MDA (3.58 - 2.88 vs. $4.13 \mu \mathrm{mol} / \mathrm{g})$, Bax and caspase-3 levels significantly ( $p<0.05$ or 0.01 ) decreased, compared with those in control group. After treatment with RV (10, 20 or $40 \mathrm{mg} / \mathrm{kg})$, GSH (16.58 - 22.14 vs. $12.34 \mu \mathrm{mol} / \mathrm{g}), \mathrm{Bcl}-2$, SOD (86.45 - $107.61 \mathrm{vs} .68 .43 \mathrm{U} / \mathrm{mg})$ and GSH-Px (295.64 329.47 vs. $268.49 \mathrm{U} / \mathrm{mg}$ ) levels or activities significantly $(p<0.05$ or 0.01$)$ increased, compared with those in control group.

Conclusion: $\mathrm{RV}$ has protective effect against $\mathrm{CCl}_{4}$-induced $\mathrm{ALI}$ in mice, and the mechanisms involve the inhibition of LPO and apoptosis in liver cells. Thus, RV is a potential drug for the treatment of liver injury
\end{abstract}

Keywords: Rhamnopyranosyl vanilloyl, Scrophularia ningpoensis, Liver injury, Protective effect, Lipid peroxidation, Apoptosis

Tropical Journal of Pharmaceutical Research is indexed by Science Citation Index (SciSearch), Scopus, International Pharmaceutical Abstract, Chemical Abstracts, Embase, Index Copernicus, EBSCO, African Index Medicus, JournalSeek, Journal Citation Reports/Science Edition, Directory of Open Access Journals (DOAJ), African Journal Online, Bioline International, Open-J-Gate and Pharmacy Abstracts

\section{INTRODUCTION}

Liver, the biggest parenchymatous organ in the human body, plays important roles in free radical metabolism, glycogen storage, secretory proteins and bile synthesis, and detoxification function. These liver functions can be damaged by liver diseases such as hepatitis, fatty liver, liver cirrhosis and liver cancer. Injury of liver cells is the common pathological foundation of liver diseases [1].

Currently, the main therapy of liver diseases is drug treatment, which requires long-term use of drugs $[2,3]$. However, the long-term use of drugs will result in development of drug resistance, 
which causes the loss of potency of drugs [4]. Thus, it is urgent to find new, safe and effective drugs to treat liver diseases.

Natural medicines are important resources to find effective drugs for treating liver diseases. Scrophularia ningpoensis Hemsl. (Scrophulariaceae) has many pharmacological activities such as analgesic, hepatoprotective, anti-oxidative, anti-fatigue, anti-cancer and anti-hypertensive activities [5-8]. Based on the hepatoprotective effect of $S$. ningpoensis, rhamnopyranosyl vanilloyl (RV), a phenolic glycoside, from $S$. ningpoensis maybe have a hepatoprotective potential. In the present study, we investigated the protective effect of $\mathrm{RV}$ against tetrachloromethane $\left(\mathrm{CCl}_{4}\right)$-induced acute liver injury $(A L I)$ in mice by monitoring liver index, liver function indices [alanine transaminase (ALT), aspartate aminotransferase (AST) and total bilirubin (TBIL)] in serum, lipid peroxidation (LPO)-related indices [malonaldehyde (MDA), glutathione (GSH), superoxide dismutase (SOD) and glutathione peroxidase (GSH-Px)] and apoptotic proteins (Bcl-2, Bax and caspase-3) in liver tissue.

\section{EXPERIMENTAL}

\section{Plant material}

S. ningpoensis was purchased from Zhong Yao Cai Tian Di Wang in 2013 and authenticated by Chang-Wu Wang, a taxonomist, who works in Department of Gastroenterology, the Fifth Affiliated Hospital of Zhengzhou University. A voucher specimen (no. FAHZZU 20131087) was deposited in the herbarium of College of Pharmacy, Zhengzhou University for future reference.

\section{Chemicals and reagents}

Analytical grade reagents (chloroform, methanol and ethanol), D101 macroporous resin and slica gel were purchased from Qingdao Haiyang Chemical Co., Ltd (Qingdao, China). Dimethyl sulfoxide (DMSO) and $\mathrm{CCl}_{4}$ were purchased from Sigma-Aldrich (Shanghai, China). Bifendate dripping pills were purchased from Beijing Union Pharmaceutical Factory (Beijing, China). Enhanced BCA Protein Assay Kit was purchased from Beyotime (Shanghai, China). ALT, AST, TBIL, MDA, GSH, SOD and GSH-Px enzymelinked immuno sorbent assay (ELISA) kits were obtained from Lengton (Shanghai, China) and Biodee (Beijing, China). Primary antibodies for $\beta$ actin, Bcl-2, Bax and caspase-3 and HRPconjugated goat anti-rabbit antibody were purchased from Abcam (Cambridge, UK) and Cell Signaling Technology (Beverly, MA, USA).

\section{Animals}

Male ICR mice $(20 \pm 2 \mathrm{~g})$ were purchased from Laboratory Animal Centre of Zhengzhou University. All experiments involving animals were conducted in accordance with the National Institute of Health Guide for the Care and Use of Laboratory Animals [9]. All animal experiments were approved by the Ethics Committee of the Fifth Affiliated Hospital of Zhengzhou University (protocol no. ECFAHZZU20141207). The animals were housed in a room at a relative humidity of $50-60 \%$, temperature of $25 \pm 2{ }^{\circ} \mathrm{C}$ and $12 \mathrm{~h}$ light/dark cycle, and received food and water ad libitum.

\section{Isolation of RV}

An air-dried $S$. ningpoensis root $(10 \mathrm{~kg})$ was powdered and extracted 4 times with refluxing 95 $\%$ ethanol to yield $873 \mathrm{~g}$ residue after evaporation of the solvent under reduced pressure. The residue was dissolved in water and then subjected to D101 macroporous resin column eluting with gradient ethanol: water. The fraction which was eluted with ethanol:water (95:5) was evaporated under reduced pressure to obtain eluate $(88 \mathrm{~g})$. Then the eluate was subjected to column chromatography over slica gel (100 - 200 mesh), and eluted with gradient chloroform: methanol to give 4 fractions. Fraction 3 was subjected to column chromatography over silica gel (100 - 200 mesh) eluting with gradient chloroform: methanol to obtain RV $(21 \mathrm{mg})$. The purity and chemical structure of RV were verified and identified by area normalization method of high performance liquid chromatography (HPLC) and nuclear magnetic resonance (NMR) data, respectively. The separation process was repeatedly carried out to obtain enough RV, dissolved in $0.5 \%$ DMSO to get different concentrations for different experiments.

\section{Grouping, treatment and modeling}

Male ICR mice were randomly divided into 6 groups ( $n=10)$ : normal, control, positive and three RV groups. Mice in the normal and control groups were orally administrated with $0.5 \%$ DMSO once a day for 7 days. Mice in the positive group were orally administrated with bifendate dripping pills at dose of $200 \mathrm{mg} / \mathrm{kg}$ once a day for 7 days. Mice in the three RV groups were orally administrated with RV at doses of 10,20 and $40 \mathrm{mg} / \mathrm{kg}$ once a day for 7 days, respectively. The volume of oral administration was $0.2 \mathrm{~mL} / 10 \mathrm{~g}$. After $2 \mathrm{~h}$ 
followed by treatment with drugs on 7th day, mice in the normal group were intraperitoneally injected with olive oil $(0.1 \mathrm{~mL} / 10 \mathrm{~g})$, and mice in other groups were intraperitoneally injected with $0.2 \% \mathrm{CCl}_{4}$ solution $(0.1 \mathrm{~mL} / 10 \mathrm{~g})$ diluted in olive oil. After fasting for $16 \mathrm{~h}$, the body weight of each mouse was measured and the orbital blood of each mouse was collected. After collecting blood, the mice were immediately sacrificed by decapitation for collecting liver tissue.

\section{Determination of ALT, AST and TBIL activities in serum}

The orbital blood was centrifuged at $4000 \mathrm{r} / \mathrm{min}$ for $10 \mathrm{~min}$ at $4{ }^{\circ} \mathrm{C}$, and then the supernatant (serum) was collected and used to determine the ALT, AST and TBIL activities. The ALT, AST and TBIL activities were determined by corresponding ELISA kits according to the manufacturers' instructions.

\section{Determination of liver index and LPO-related indices}

The liver tissue of mice was washed with cold normal saline, blotted dry, weighed, and homogenized in cold normal saline to obtain 10 $\%$ liver tissue homogenate. This homogenate was centrifuged at $4000 \mathrm{r} / \mathrm{min}$ for $10 \mathrm{~min}$ at $4{ }^{\circ} \mathrm{C}$, and then the supernatant was collected and used to determine the MDA and GSH levels and the SOD and GSH-Px activities by corresponding ELISA kits according to the manufacturers' instructions. Liver index was calculated as the liver weight/body weight ratio.

\section{Determination of $\mathrm{Bcl}-2$, Bax and caspase-3 proteins levels}

Bcl-2, Bax and caspase-3 proteins levels in liver tissue were determined by Western blot. The total proteins of liver tissue were extracted and then the concentration was determined using Enhanced BCA Protein Assay Kit. Total proteins (about $35 \mu \mathrm{g}$ ) were separated by sodium dodecyl sulfate-polyacrylamide gel electrophoresis and then transferred onto a polyvinylidene difluoride (PVDF) membrane. After blocking with $5 \%$ fatfree milk, PVDF membranes were incubated with the corresponding primary antibodies for $\beta$-actin, $\mathrm{Bcl}-2$, Bax and caspase-3 overnight at $4{ }^{\circ} \mathrm{C}$. Subsequently, the PVDF membranes were washed and incubated with HRP-conjugated goat anti-rabbit antibody at room temperature for 2 h. Then, proteins were detected by chemiluminescence detection. $\beta$-actin was used as an internal control for equal protein loading.

\section{Statistical analysis}

All data are presented as mean \pm standard deviation (SD). Differences between two groups were analyzed by one-way ANOVA using SPSS 21.0. Differences were considered as statistically significant at $p<0.05$ or 0.01 .

\section{RESULTS}

\section{Purity and chemical structure of RV}

The purity of RV was $98.3 \%$ verified by area normalization method of HPLC, and it was identified by comparing the NRM data with the existing literature $[10,11]$. The chemical structure is shown in Figure 1.<smiles>COc1cc(C(=O)O)ccc1OC1[C@H](O)O[C@H](C)[C@H](O)[C@H]1O</smiles>

Figure 1: Chemical structure of RV

\section{Effect of RV on liver index}

As shown in Figure 2, the liver index (6.68 \pm 0.61 $\%$ ) in the control group was significantly ( $p<$ $0.01)$ higher than that in the normal group (4.85 \pm $0.24 \%)$, and the liver index (4.99 $\pm 0.29 \%)$ in the positive group was significantly $(p<0.01)$ lower than that in the control group. After treatment with RV $(10,20$ or $40 \mathrm{mg} / \mathrm{kg})$, the liver index (5.65 $\pm 0.25-5.21 \pm 0.25 \%)$ was significantly $(p<0.01)$ decreased, compared with that in the control group.

\section{Effect of RV on serum ALT, AST and TBIL}

As presented in Table 1, the ALT, AST and TBIL activities in the control group were significantly ( $p$ $<0.01$ ) higher than those in the normal group, and the ALT, AST and TBIL activities in the positive group were significantly $(p<0.01)$ lower than those in the control group. After treatment with RV $(10,20$ or $40 \mathrm{mg} / \mathrm{kg})$, the ALT, AST and TBIL activities were significantly $(p<0.01)$ decreased, compared with those in the control group. 


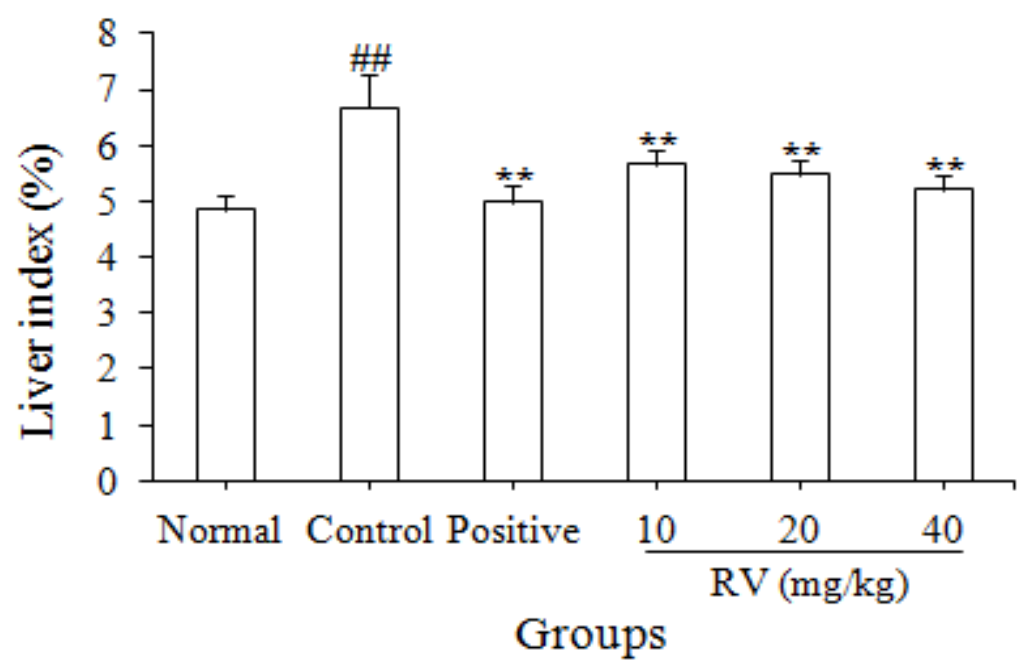

Figure 2: Improved effect of RV on liver index in mice with $\mathrm{CCl}_{4}$-induced $\mathrm{ALI},{ }^{\#} p<0.01$, compared with that in the normal group; ${ }^{* *} p<0.01$, compared with that in the control group

Table 1: Inhibitory effect of RV on serum ALT, AST and TBIL activities in mice with $\mathrm{CCl}_{4}$-induced ALI

\begin{tabular}{|c|c|c|c|}
\hline Group & ALT (U/L) & AST(U/L) & TBIL(U/L) \\
\hline Normal & $74.38 \pm 13.05$ & $43.87 \pm 8.65$ & $0.81 \pm 0.19$ \\
\hline Control & $112.47 \pm 11.89^{\# \#}$ & $75.41 \pm 12.48^{\# \#}$ & $3.21 \pm 0.68^{\# \#}$ \\
\hline Positive & $78.64 \pm 12.19^{n}$ & $54.37 \pm 10.40^{n}$ & $1.68 \pm 0.24 n$ \\
\hline $\mathrm{RV}(10 \mathrm{mg} / \mathrm{kg})$ & $90.18 \pm 11.45^{x x}$ & $64.44 \pm 9.71$ & $2.68 \pm 0.39$ \\
\hline $\mathrm{RV}(20 \mathrm{mg} / \mathrm{kg})$ & $83.45 \pm 12.89^{\text {xx }}$ & $60.90 \pm 10.87^{\pi}$ & $2.34 \pm 0.41^{\text {*x }}$ \\
\hline $\mathrm{RV}(40 \mathrm{mg} / \mathrm{kg})$ & $79.68 \pm 10.75^{\pi \pi}$ & $57.63 \pm 11.24^{\pi \pi}$ & $1.95 \pm 0.37^{\pi \pi}$ \\
\hline
\end{tabular}

Effect of RV on MDA, GSH, SOD and GSH-Px levels or activities

As shown in Table 2, the MDA level in the control group was significantly $(p<0.01)$ higher than that in the normal group, and the GSH level and the SOD and GSH-Px activities in the control group were significantly $(p<0.01)$ lower than those in the normal group. The MDA level in the positive group were significantly $(p<0.01)$ lower than that in the control group, and the GSH level and the SOD and GSH-Px activities in the positive group were significantly $(p<0.01)$ higher than those in the control group. After treatment with RV $(10,20$ or $40 \mathrm{mg} / \mathrm{kg})$, the MDA level were significantly $(p<0.01)$ decreased, and the GSH level and the SOD and GSH-Px activities were significantly $(p<0.05$ or 0.01$)$ increased, compared with those in the control group.

\section{Effect of RV on Bcl-2, Bax and caspase-3 proteins levels}

As shown in Figure 3, the $\mathrm{Bcl}-2$ protein level in the control group was significantly $(p<0.01)$ lower than that in the normal group, and the Bax and caspase- 3 proteins levels in the control group were significantly $(p<0.01)$ higher than those in the normal group.

Table 2: Reversed effect of RV on MDA, GSH, SOD and GSH-Px levels or activities in liver tissue of mice with $\mathrm{CCl}_{4}$-induced ALI

\begin{tabular}{|c|c|c|c|c|}
\hline Group & MDA ( $\mu \mathrm{mol} / \mathrm{g})$ & GSH $(\mu \mathrm{mol} / \mathrm{g})$ & SOD (U/mg) & GSH-Px (U/mg) \\
\hline Normal & $2.12 \pm 0.09$ & $27.64 \pm 3.89$ & $135.14 \pm 13.75$ & $357.21 \pm 45.73$ \\
\hline Control & $4.13 \pm 0.34^{\# \#}$ & $12.34 \pm 1.95^{\# \#}$ & $68.43 \pm 10.54^{\# \#}$ & $268.49 \pm 28.97^{\# \#}$ \\
\hline Positive & $2.67 \pm 0.18^{n}$ & $18.57 \pm 2.54$ & $128.47 \pm 12.47^{n}$ & $334.58 \pm 30.21^{n}$ \\
\hline $\mathrm{RV}(10$ mg/kg) & $3.58 \pm 0.31^{\pi \pi}$ & $16.58 \pm 2.13^{\pi \pi}$ & $86.45 \pm 9.18^{\pi x}$ & $295.64 \pm 27.81^{\pi}$ \\
\hline $\mathrm{RV}(20 \mathrm{mg} / \mathrm{kg})$ & $3.14 \pm 0.35^{\pi x}$ & $20.47 \pm 2.86^{\pi \pi}$ & $98.37 \pm 10.39^{\text {xx }}$ & $318.79 \pm 30.24^{\pi \pi}$ \\
\hline $\mathrm{RV}(40 \mathrm{mg} / \mathrm{kg})$ & $2.88 \pm 0.27^{\prime \prime}$ & $22.14 \pm 3.02^{n}$ & $107.61 \pm 12.48^{n}$ & $329.47 \pm 34.63^{n-}$ \\
\hline
\end{tabular}



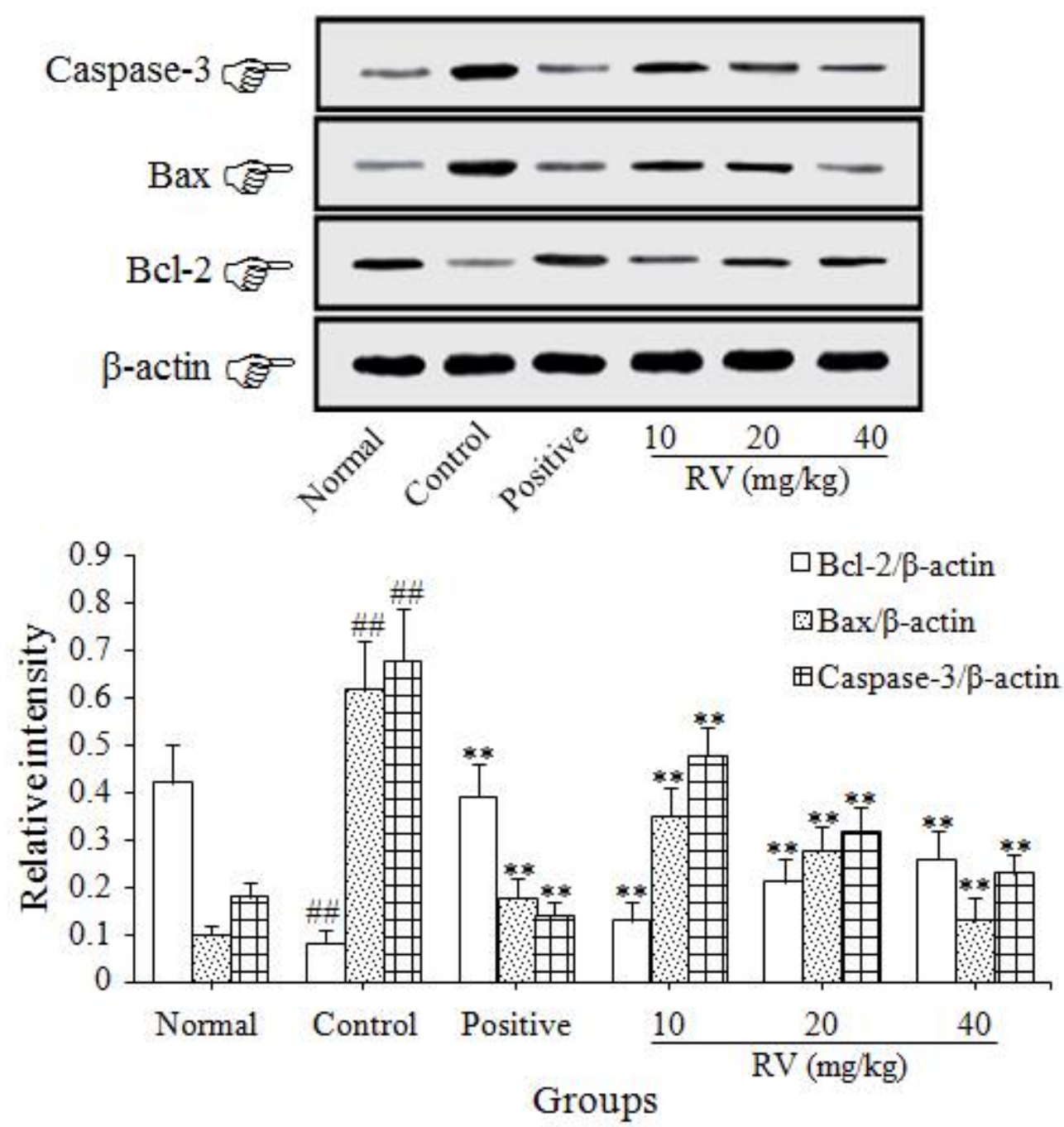

Figure 3: Reversed effect of RV on Bcl-2, Bax and caspase-3 proteins levels in liver tissue of mice $\mathrm{CCl}_{4}$-induced ALI, ${ }^{\#} p<0.01$, compared with those in the normal group; ${ }^{* *} p<0.01$, compared with those in the control group

The Bcl-2 protein expression in the positive group was significantly $(p<0.01)$ higher than that in the control group, and the Bax and caspase- 3 proteins expressions in the positive group were significantly $(p<0.01)$ lower than those in the control group. After treatment with RV $(10,20$ or $40 \mathrm{mg} / \mathrm{kg}$ ), the Bcl-2 protein level was significantly $(p<0.01)$ increased, and the Bax and caspase- 3 proteins levels were significantly $(p<0.01)$ decreased, compared with those in the control group.

\section{DISCUSSION}

$\mathrm{CCl}_{4}$-induced $\mathrm{ALI}$ is an accepted model for investigating the protect effect of drugs against liver injury [12]. The mechanisms of $\mathrm{CCl}_{4}$ induced ALI were related to the generation of free radicals and activated oxygen species, LPO, denaturation of proteins, DNA damage and induction of apoptosis $[13,14]$. Based on the fact that bifendate dripping pills, commonly used to treat liver diseases, can relieve the $\mathrm{CCl}_{4}$-induced $A L I$, it was used as the positive control drug in this work $[1,15]$.

Liver index can macroscopically reflect liver functions, and liver index is increased in mice with $\mathrm{CCl}_{4}$-induced ALI [16]. Generally, ALT and AST are mainly distributed in liver cells, and the ALT and AST are released from liver cells to blood in rats with $\mathrm{CCl}_{4}$-induced $\mathrm{ALI}$ [17]. The ability of liver to conjugate and excrete bilirubin is increased after liver injury, resulting in the increase of TBIL level in blood [18]. The level of MDA, an important product of LPO, can reflect the degree of tissue LPO damage, and the MDA level is increased in liver tissue of mice with $\mathrm{CCl}=$-induced ALI [19]. SOD inhibits the free radicals-mediated LPO. GSH-mediated hydrogen peroxide reduction reaction, which can protect the structure and function of cytomembrane, is catalyzed by GSH-Px [20]. Therefore, SOD, GSH and GSH-Px exhibit protective effects against 
LPO damage. The GSH level and the SOD and GSH-Px activities in liver tissue of mice with $\mathrm{CCl}_{4}$-induced $\mathrm{ALI}$ are decreased due to the occurrence of LPO [19]. Anti-apoptotic protein $(\mathrm{Bcl}-2)$ and pro-apoptotic proteins (Bax and caspase-3) play important roles in mitochondriamediated apoptotic pathway [21]. After $\mathrm{CCl}_{4-}$ induced liver injury, the Bcl-2 protein level in liver tissue is decreased and the Bax and caspase- 3 proteins levels are increased due to the $\mathrm{CCl}_{4}$ mediated apoptosis of liver cells [14,22].

In the present study, after mice were intraperitoneally injected with $\mathrm{CCl}_{4}$, liver index, ALT, AST and TBIL activities in serum and MDA, Bax and caspase- 3 levels in liver tissue were increased, and GSH, Bcl-2, SOD and GSH-Px levels or activities in liver tissue were decreased. The results indicate that the $\mathrm{CCl}_{4}$-induced $\mathrm{ALI}$ model was successfully established by inducing LPO and apoptosis of liver cells, which was similar to the previous reports [12-14]. After mice with $\mathrm{CCl}_{4}$-induced $\mathrm{ALI}$ were treated with positive drug (bifendate dripping pills), the changes of above indices were reversed. The results suggest that the positive drug showed protective effect against $\mathrm{CCl}_{4}$-induced ALI by inhibiting LPO and apoptosis of liver cells, which was similar to the previous reports [1,15]. After mice with $\mathrm{CCl}_{4}{ }^{-}$ induced $A L I$ were treated with $R V$, the changes of above indices were also reversed, suggesting that RV shows protective effect against $\mathrm{CCl}_{4-}^{-}$ induced $A L I$ in mice by inhibiting LPO and apoptosis of liver cells.

\section{CONCLUSION}

RV displays significant protective effect against $\mathrm{CCl}_{4}$-induced ALI in mice. The mechanisms of this action might be related to the inhibition of LPO and apoptosis in liver cells. Thus, RV is a potential drug for the treatment of liver injury. This, however, needs to be further investigated to ascertain the actual potentials of RV.

\section{DECLARATIONS}

\section{Conflict of Interest}

No conflict of interest associated with this work.

\section{Contribution of Authors}

The authors declare that this work was done by the authors named in this article and all liabilities pertaining to claims relating to the content of this article will be borne by them.

\section{REFERENCES}

1. Zhang $Y$, Yang $C F$, Yang $Y$, Wang $D$, Zhang $Q H$. Protective effect of Cassia nomame against acute liver injury induced by CCl4 and ethanol in mice. Chin J Exper Tradit Med Formu 2015; 21(10): 137-140.

2. Stickel F, Schuppan D. Herbal medicine in the treatment of liver diseases. Dig Liver Dis 2007; 39(4): 293-304.

3. Hosaka T, Suzuki F, Kobayashi M, Seko Y, Kawamura Y, Sezaki $H$, et al. Long-term entecavir treatment reduces hepatocellular carcinoma incidence in patients with hepatitis B virus infection. Hepatology 2013; 58(1): 98107.

4. Pietersen $E$, lqnatius $E$, Streicher EM, Mastrapa $B$, Padanilam X, Pooran A, et al. Long-term outcomes of patients with extensively drug-resistant tuberculosis in South Africa: a cohort study. Lancet 2014; 383(9924): 1230-1239.

5. Xie XY, Xia CS. Advances in studies on chemical constituents and pharmacological activities of Scrophularia ningpoensis Hemsl. Asia-Pacific Tradit Med 2010; 6(5): 121-125.

6. Han JJ, Ning N. Research progress on pharmacological effects of Scrophularia ningpoensis. Strait Pharmaceut $J$ 2014; 26(12): 97-99.

7. Liu GZ, Dong WR, Yu H, Gao X, Li ZH, Liu SM. Scrophularia ningpoensis Hemsl. for CCl4-induced liver injury in rats. Jilin J Tradit Chin Med 2015; 35(5): 504507.

8. Sun $\mathrm{K}$, Jiang $\mathrm{H}$. The protective activity to hepatocytes of phenylpropanoid glycosides from Scrophularia ningpoensis. J Pharmaceut Prac 2002; 20(4): 234-235.

9. National Institute of Health. USA. Public health service policy on human care and use of laboratory animals, 2002.

10. Liu YF, Liang D, Luo H, Hao ZY, Wang Y, Zhang CL, et al. Chemical constituents from root tubers of Rehmannia glutinosa. China Tradit Herb Drugs 2014; 45(1): 16-22.

11. Xue GQ, Du J, Pan XY, Gao H, Sun ZY, Zhang Y, Gao $S L$. Chemical constituents of Scrophularia ningpoensis root. J Chin Med Mater 2014; 37(9): 1597-1599.

12. Abbas AT, El-Shaitany NA, Shaala LA, Ali SS, Azhar El, Abdel-Dayem UA, Youssef DT. Red sea subarea mollis sponge extract protects against CCl4-induced acute liver injury in rats via antioxidant mechanism. Evid Based Complement Alternat Med 2014; 2014: 745606.

13. Bu XJ. Progress on animal models of liver injury research. China Med Herald 2014; 11(12): 166-168.

14. Chakraborty JB, Oakley F, Walsh MJ. Mechanisms and biomarkers of apoptosis in liver disease and fibrosis. Int J Hepatol 2012; 2012: 648915.

15. Zhang $W$, Huang $L$, Chen $Y X$, Sun SJ, Jiang BP, $X u L$. Protective effect of compound Long Chuicao decoction on CCl4-induced acute liver injury in mice. Tradit Chin Drug Res Clin Pharmacol 2015; 26(3): 280-284.

16. Lu B, Xu Y, Xu L, Cong $X$, Yin L, Li H, Peng J. Mechanism investigation of dioscin against CCl4- 
induced acute liver damage in mice. Environ Toxicol Pharmacol 2012; 34(2): 127-135.

17. Cetinkaya A, Kantarceken B, Bulbuloglu E, Kurutas EB, Ciralik $H$, Atli $Y$. The effects of L-carnitine and $N$ acetylcysteine on carbontetrachloride induced acute liver damage in rats. Bratis/ Lek Listy 2013; 114(12): 682-688.

18. Zhao DM. Veterinary pathology. Beijing: China Agricultural University Press; 2005, pp 106.

19. Cheng N, Ren N, Gao H, Lei X, Zheng J, Cao W. Antioxidant and hepatoprotective effects of Schisandra chinensis pollen extract on CC/4-induced acute liver damage in mice. Food Chem Toxicol 2013; 55: 234-240.
20. Wang HF, Zhong XH, Shi W, Guo B. Study of malondialdehyde (MDA), superoxide dismutase (SOD) and glutathione peroxidase (GSH-Px) activities in chickens infected with avian infectious bronchitis virus. Afr J Biotechnol 2011; 10(5): 9213-9217.

21. Shi Y. A structure view of mitochondria-mediated apoptosis. Nat Struct Biol 2001; 8(5): 394-401.

22. Lee TY, Chang HH, Wang GJ, Chiu JH, Yang YY, Lin HC. Water-soluble extract of Salvia miltiorrhiza ameliorates carbon tetrachloride-mediated hepatic apoptosis in rats. J Pharm Pharmacol 2006; 58(5): 659665. 